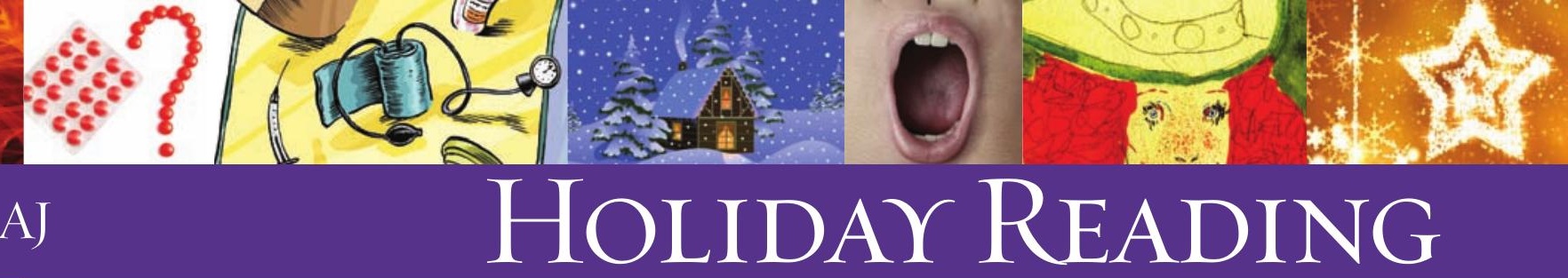

QUIZ

\title{
Learning medicine through riddles
}

\section{Each riddle is an autobiography of a drug. Name it.}

1. My US and UK names differ Those bothered by sulfa may suffer

I'm sequestered at the site of action

Weight gain is my adverse reaction

2. I'm polypeptide in nature

Sourced from a poisonous creature I mimic the gut hormone in action Pancreatitis my serious reaction

3. I got into the limelight by Modulating gene expression But peripheral edema Created a bad first impression Raised liver enzymes just Added fuel to the flame

Cardiovascular events

On the increase made me lame

4. I am extracted from a goat's rue After just one months' therapy, My benefit is due Anorexia is my beneficial side-effect Dose division will lesse My main adverse effect

5. Named after my structural modification A common metabolic Disorder my indication I'm very rapid in action And least variable in absorption

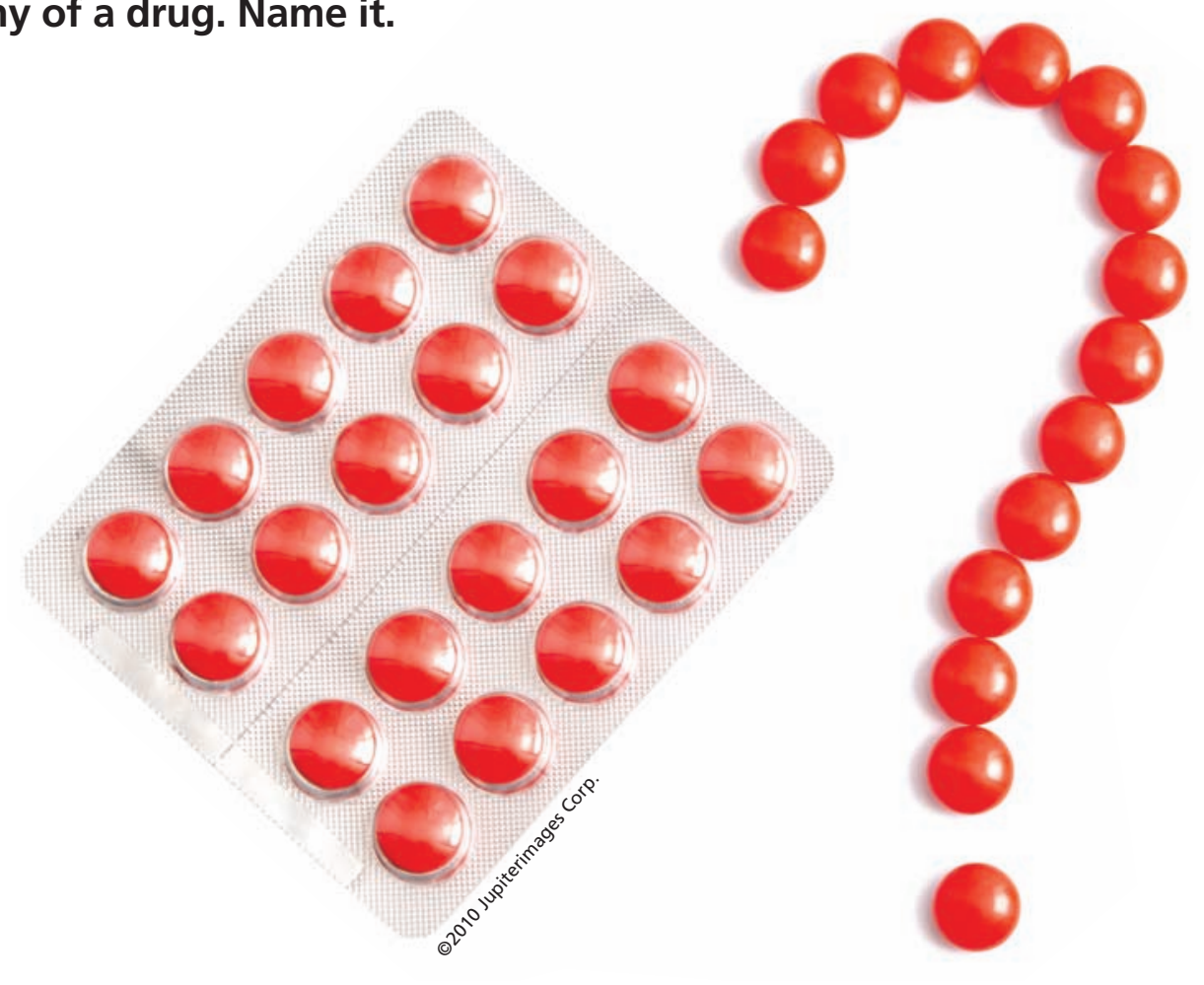

6. Born in 19th century for gout But later served a different bout Tiny in structure; tardy in action Hypothyroidism and Tremor my adverse reactions

\section{S. Manikandan}

\section{Assistant professor}

Department of Pharmacology

Indira Gandhi Medical College and Research Institute

\& Pondicherry, India.

Dr. N. Isai Vani

Assistant professor

Department of Anatomy

Indira Gandhi Medical College and Research Institute

Pondicherry, India

ANSWERS ON THE NEXT PAGE

(no peeking) 


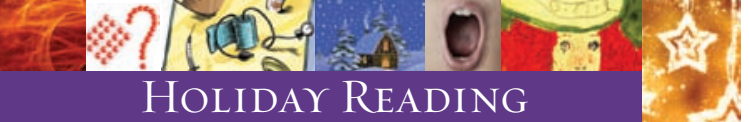
Answers
1. Glibenclamide/Glyburide
2. Exenatide
3. Rosiglitazone
4. Metformin
5. Insulin lispro
6. Lithium

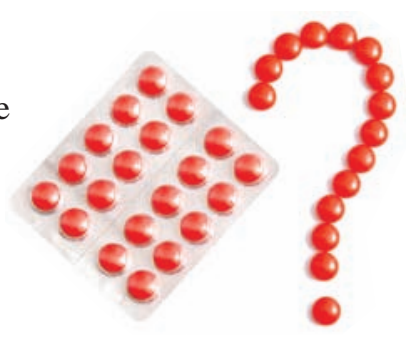

